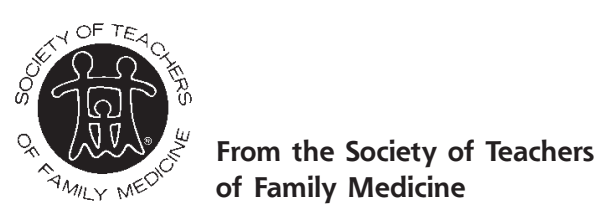

Ann Fam Med 2005;3:281. DOI: 10.1370/afm.323.

\section{STFM OPENS FAMILY MEDICINE DIGITAL RESOURCES LIBRARY}

In late 2004, the Society of Teachers of Family Medicine was awarded a 3-year grant expected to total approximately $\$ 400,000$ by the National Library of Medicine to develop the Family Medicine Digital Resources Library (FMDRL). FMDRL will provide an administrative and technical framework for the dissemination, review, revision, archiving, and maintenance of presentations, learning modules, quizzes, examinations, simulated clinical cases, and other curricular materials. This library will include curricular materials from all levels of family medicine education.

The vision for FMDRL is to be the primary mechanism used by family medicine educators to share curricular materials-resulting in efficient, effective dissemination of curricular materials nationally and internationally. Efforts will be made to build and maintain a critical mass of content related to the core strategic goals of STFM. The library is being developed with an open standards-based infrastructure, permitting interaction with other digital libraries, such as the Health Education Assets Library.

Editorial and administrative oversight for FMDRL will be provided by a steering committee of educators, informaticists, researchers, and librarians. Jacob Reider, MD, Albany Medical College, serves as steering committee chair, and Roger Sherwood, CAE, STFM executive director, as principal investigator for the grant. Other FMDRL Steering Committee members include Helen Baker, PhD, MBA, West Virginia School of Osteopathic Medicine; Richard Usatine, MD, University of Texas HSC at San Antonio; Enid Geyer, MLS, Albany Medical College; Mary Moore, PhD, University of Texas HSC at San Antonio; and Traci Nolte, STFM communications director.

The FMDRL Steering Committee would like acknowledge the dedicated work of the University of Washington, the STFM Group on Faculty Development, and the STFM Group on Evidence-based Medicine for their creation of a pilot Web site that has provided the FMDRL development team with valuable information and feedback as we move forward on the development of this resource.

At the recent STFM Annual Spring Conference, held April 30 to May 4 in New Orleans, members of both the pilot Web site and the FMDRL Steering Committee presented a seminar and spoke to chairs of STFM special interest groups about the FMDRL and how STFM members can become involved in the success of this valuable resource for family medicine educators.

For more information on the FMDRL or to find out how you can get involved, visit http://www.fmdrl. org or contact FMDRL staff liaison, Traci Nolte, at tnolte@stfm.org.

Traci Nolte

STFM Communications Director

$\begin{array}{ll}\text { NORTH } & \\ \text { AMERICAN } & \\ \text { PRIMARY CARE } & \text { From the North American } \\ \text { RESEARCH } & \text { Primary Care Research Group }\end{array}$

Ann Fam Med 2005;3:281-282. DOI: 10.1370/afm.320.

\section{LEARNING BY DOING: MENTORING, HANDS-ON EXPERIENCE KEYS TO WRITING SUCCESSFUL RESEARCH GRANTS}

The best way to learn grantsmanship is through the process of actually writing a grant, under the guidance of an experienced researcher, says Kevin Peterson, MD, assistant professor in the Department of Family Practice and Community Health at the University of Minnesota. Dr Peterson, who has chalked up more than $\$ 9$ million in funding as principal investigator (PI) for 8 major grants and subcontracts since 1998, was one of the first Grant Generating Project (GGP) fellows, when the program was launched by NAPCRG's Committee on Building Research Capacity in the 1995-1996 academic year. He exemplifies the skills and characteristics GGP has sought to develop and strengthen in its fellows during the past decade.

One of the most important things Dr Peterson gained from GGP, he says, was "the ability to develop relationships with outstanding researchers."

"One of the best things that happened to me with GGP," he says, "was that it introduced me to Paul Nutting, MD. Paul introduced me to some other great researchers involved in practice-based research." Dr Nutting, director of research for the Center for Research Strategies in Denver, Colo, is one of the many experienced family medicine researchers who have served as consultants and mentors for GGP.

Networking with other researchers has continued to be a major focus of Dr Peterson's work. He was instrumental in organizing the Federation of Practicebased Research Networks (FPBRN) in 1997 and now serves as chair of the FPBRN Steering Committee. He 
is also director of the Minnesota Academy of Family Physicians Research Network. He has extended his collaboration internationally, working with researchers at University of Birmingham toward developing an electronic application for use in practice-based research in the United States, United Kingdom, and Europe.

Dr Peterson acknowledges he was not instantly successful in his efforts to obtain a major National Institutes of Health (NIH) grant. His proposal on translating empirical knowledge regarding diabetes care into primary care practice was rejected twice by the Agency for Healthcare Research and Quality (AHRQ), he recalls, then submitted to both AHRQ and National Institute of Diabetes and Digestive and Kidney Diseases (NIDDK), and then rewritten again when NIDDK indicated interest in funding the project without AHRQ. His perseverance was ultimately rewarded with a 4-year, \$1.6 million grant from NIDDK.

More recently, he received a $\$ 3$ million NIH Roadmap Award for a project titled "The Electronic Primary Care Research Network (ePCRN)." Dr Peterson is the principal investigator for the project, which is being conducted by FPBRN in cooperation with the AAFP' Center for Health Information Technology and the University of Minnesota. The project will put in place an electronic infrastructure to provide support for FPBRN members. Among its capabilities will be providing clinics with a standard patient registry, interactive videoconferencing, and enabling of clinic-based controlled trials.

Dr Peterson is also PI for a $\$ 3.4$ million subcontract with National Heart, Lung, and Blood Institute and NIDDK, for a randomized trial to evaluate the effect of tight glycemic, blood pressure, and lipid control on cardiovascular morbidity and mortality in patients with diabetes.

While working toward these major grants, Dr Peterson successfully obtained funding of a number of smaller grants for his work in diabetes care and translational research.

The value of these smaller grants is in the experi- ence they provide, he says. "They introduced me to better methodologies," such as how to develop recruitment and data collection strategies, and what things are important in data abstraction.

"When you write your first NIH grant, there's just so much to learn," he says. Critically important is understanding what $\mathrm{NIH}$ wants to investigate. NIH has a program that brings in experts to establish research priorities for the nation, and then puts billions of dollars into doing that research, Dr Peterson explains. The challenge for the research mentor in family medicine is getting the individual's interest to mesh with the interests of the country.

"Mentoring, to me, is the most valuable aspect of GGP," Dr Peterson says. "You can learn all about the PHS 398 from a master's class, but it's different when you actually do it."

Mentoring is a key component of GGP, with each fellow expected to select a mentor who will work with $\mathrm{him} /$ her throughout the fellowship year and provide critical feedback on the grant in progress. GGP workshop faculty/consultants provide additional expertise in a range of areas including grantwriting, literature search and review, study design, and statistics.

Building on skills learned or honed during their GGP fellowship year, along with making the most of opportunities for further networking and skill development, Dr Peterson and other GGP alumni have been awarded grants and contracts totaling more than $\$ 32$ million for family medicine research and training. Not counted in that figure is the additional impact these fellows have as they mentor others in their home departments and contribute toward others' grants as collaborators or informal advisers.

For more information on GGP, visit the GGP Web site, at http://www.fcm.missouri.edu/research-ggp.htm.

Daniel R. Longo GGP Project Director Shari Schubert GGP Project Coordinator 